\title{
A quantitative approach for delineating principal fairways of ship passages through a strait
}

\author{
Jinhai Chen ${ }^{\mathrm{a}, \mathrm{b}, *}$, Feng Lu ${ }^{\mathrm{a}, \mathrm{c}, *}$, Guojun Peng ${ }^{\mathrm{b}}$ \\ a State Key Laboratory of Resources and Environmental Information System, Institute of Geographic Sciences and Natural Resources Research, \\ Chinese Academy of Sciences, Beijing 100101, China \\ ${ }^{\mathrm{b}}$ Marine Navigation \& Pilot Technology Research Centre, Navigation College, Jimei University, Xiamen 361021, China \\ ' Jiangsu Center for Collaborative Innovation in Geographical Information Resource Development and Application, Nanjing 210023, China
}

\section{A R T I C L E I N F O}

\section{Article history:}

Received 26 September 2014

Accepted 29 April 2015

Available online 27 May 2015

\section{Keywords:}

Principal fairways

Space use

Ship trajectories

Ship routing system

Taiwan Strait

AIS

\begin{abstract}
A B S T R A C T
Seamen usually select popular routes according to navigational and hydrographical characteristics when passing through a strait with congested traffic. In order to minimise the possibility of collisions, Principal Fairways (PFs) are commonly used by sailors. It is essential to delineate PFs quantitatively and objectively for designing or refining routing measures. In this paper, a space use method found in habitat evaluation of wildlife is applied to extract PFs of ship passages through a strait. Compared with existing methods, the proposed method helps to identify cumulative activity patterns for ship groups derived from mass ship trajectories, and provides a clearer interpretation of shifting space-use patterns within strait corridors. Moreover, it gives a better insight for directional and seasonal factor for PFs in straits. Finally, this novel method is used to extract PFs in western Taiwan Strait and its adjacent sea. The results indicate that the proposed method is helpful to identify gaps between current ship routing system plan and cumulative activity patterns recognised by real ship trajectories.
\end{abstract}

(c) 2015 Elsevier Ltd. All rights reserved.

\section{Introduction}

There were various traditional observations to extract shipping routes due to the application of Voice Radio Communication and Radar in tracking vessel in the 20th century (Schwehr, 2011). Thousands of European antecedent voyages across the oceans were extracted from ship logbooks in the age of sail (Können and Koek, 2005); Radar data were implemented to create ship routing system of Dover Strait (Johnson, 1973); Global commercial ship lanes were abstracted by using of locations reported by 3374 voluntary observing ships in a period of 12 months (Halpern et al., 2008). However, traditional records were just sparse samples and

\footnotetext{
Abbreviations: AIS, automatic identification system; ANR, application nautical range; CCSRSP, China's Coastal Ships Routing System Plan; CMSA, China Maritime Safety Administration; ER, exponential regression; EF, equivalent factor; IMO, International Maritime Organisation; KDE, kernel density estimation; IV, isopleths volume; LCP, least cost path; LOA, length over all; PA, precautionary area; PF, principal fairway; SD, standard deviation; SNR, specific nautical range; SUD, shipping utilisation distribution; TSS, traffic separation schemes; UD, utilisation distribution; WF, weighted frequency

* Corresponding authors at: State Key Laboratory of Resources and Environmental Information System, Institute of Geographic Sciences and Natural Reso urces Research, Chinese Academy of Sciences, Beijing 100049, China. Tel.: +8610 64888966; fax: +861064889630.

E-mail addresses: jhchen@jmu.edu.cn (J. Chen), luf@lreis.ac.cn (F. Lu), penggj1314@126.com (G. Peng).
}

shipping traffic was not captured by these data. Fortunately, nearly all seagoing merchant ships and passenger ships are required to carry an Automatic Identification System (AIS) according to current mandates released by the International Maritime Organisation (IMO). The wide deployment of AIS allows ships be tracked in $24 \mathrm{~h}$ per day. Meanwhile the emerging technology of space-based AIS provides a global coverage of the maritime domain including in the open sea (Guillarme and Lerouvreur, 2013). Recent advances in ship tracking and telemetry technology help to collect the movement tracks more efficiently and accurately. The ship tracks have increased tremendously, and these advances have been accompanied by the development of new methods, which serve for marine transport planning especially in crowed shipping areas, such as straits.

Straits are shortcuts between two large water bodies. These passageways generally host large amounts of traffic volume with various directions. Thus, the risk of collision between ships is higher in straits than in other waterways (Klanac et al., 2010; Qu et al., 2011). This congest situation will become even worse with the massive increase in global shipping. To minimise the possibility of collisions in ships passage straits, states bordering certain congested straits may create routing systems to separate vessels, control crossing and meeting situations. Developing ship routing schemes in congested straits have become an important topic in maritime transport, especially the straits heavily used for international navigation, such as the Dover Strait (Johnson, 1973; Squire, 
2003) the Istanbul Strait (Aydogdu et al., 2012), and the Malacca Strait (Qu et al., 2011; Zaman et al., 2014). However, only 15 straits throughout the world have implemented Traffic Separation Schemes (TSS) approved by the IMO (UKHO, 2012). Vessels are required to follow certain sea lanes in those TSS areas. There are improvements for other straits on keeping ship traffic flows in good order. The selection and development of routing systems are the responsibility of maritime administrators. Within this context, such administrators should consider various factors, including the knowledge of Principal Fairways (PFs), existing navigation aids, the state of hydrographic surveys in the area and accepted standards of routing (IMO, 2003). There are always attractive and popular routes accessible to sailors with respect to navigational and hydrographical characteristics through a given strait. PFs are the water areas commonly used by sailors and have a large traffic volume, which are believed to be the most economical sailing method. Thus they are empirically significant in recommended routes for sailors. In previous work involved ship routing system on straits (Aydogdu et al., 2012), PFs (so-called main traffic flows) are subjectively selected based on mariners' experience, which is not quantitatively repeatable.

Perceiving how mobile objects move about space is a fundamental research question in Geographic Information Science, and there are many quantitative methods for analyzing movement data (Long and Nelson, 2012). Of these, Origin-Destination matrices is arguably the most straightforward method to represent routes in a network (Christiansen et al., 2013). It is also accepted in maritime/ ocean engineering literature. For example, Kaluza et al. (2010) extracted 490,517 routes linking 36,351 distinct pairs of OriginDestination in annual global AIS database to represent the global shipping network. Eight main Origin-Destinations were defined as main routes in the Istanbul Strait (Aydogdu et al., 2012). However the method of Origin-Destination matrices only concerns the origin and destination of each movement but ignores the actual trajectories. One of the potential solution is Route Topology Modelling appliance, where routes are abstracted into a topology model composed of discrete legs, junctions, nodes and their associated attributions like urban road network (Oltmann, 2014). However, the maritime environment remains an open space where navigation in any direction is allowed. Thus, the shipping network is rather different from the road network, which is known a priori to construct corresponding urban road topology (Tsatcha et al., 2014).

It is important to keep in mind that in maritime/ocean engineering communities, the goal of sea-lanes identification is to preserve navigational safety rather than to port accessibility(Christiansen et al., 2013). This is the reason why a manual strategy is adopted in fairways selection (Fowler and Sørgård, 2000; Montewka et al., 2012). van Dorp and Merrick (2011) applied an automated filtering process to clean noisy routes and define ideal trajectories in simulator. Tzavella and Ulmke (2014) proposed a semi-automatic sea-lane extraction approach with particle filtering. Apart from manual, supervised and semi-automatic approach, there are other various unsupervised strategies of fairway extraction, such as image processing technique (Aarsæther and Moan, 2009), shared nearest neighbour algorithm (Santos et al., 2012), density-based clustering of ships' waypoints algorithm (Arguedas et al., 2014a,b; Pallotta et al., 2014, 2013). Those existing methods of ship route extraction just concern waypoints, then give a continuous line or labeled (clustered) track-lines set. Their results were representative of a sea-lane, but ignore the boundary and utilisation distribution of principal fairways. In terms of maritime corridors identification on the whole, it is clear that dedicated efforts should be directed to increase scientific understanding of PFs.

There is a wide variety of maritime quantitative methods focus on ship-ship collision risk assessment (Li et al., 2012). The fundamental principles consist of finding a number of vessel conflicts in nautical traffic data (e.g. AIS, Radar) and assigning a probability to each of these conflicts. Many maritime accident risk model have been proposed, such as blind navigation collision candidates methods (Fowler and Sørgård, 2000; Goerlandt and Kujala, 2011; Montewka et al., 2012; Otto et al., 2002), traffic simulation methods (Asmara et al., 2014; Blokus-Roszkowska and Smolarek, 2012; Goerlandt et al., 2012; van Dorp and Merrick, 2011), traffic indices methods (Qu et al., 2011; Suman et al., 2012), Bayesian networks methods (Montewka et al., 2014), fuzzy methods (Sahin and Senol, 2015; Zaman et al., 2014), evolutionary algorithms (Szlapczynski, 2013), Ship Domain methods (Montewka et al., 2012). Among them, Ship Domain methods were widely applied in the geometrical probability of encounter after the pioneering works of Fujii and Shiobara (1971), Goodwin (1975).

There are various definition of Ship Domain, such as a description based on characteristics of vessels engaged in emergency maneuvering (Montewka et al., 2012; Zhang et al., 2012), an empirical domain based on AIS data (Hansen et al., 2013), a dynamic quaternion model with fuzzy boundaries (Wang, 2013). Meanwhile SD could be regarded as a factor for determining the width of a fairway (Jensen et al., 2013). However, there is still highly uncertain in the definition of Ship Domain and vessel encounter (Goerlandt and Kujala, 2014; Sormunen et al., 2014).

The existing methods only provided low-level contextual information of PFs, such as waypoints through track-lines, and the direction on each leg. It indicates a need for next generation of quantitative method to discover high-level knowledge concerning capturing PFs boundaries and understanding changes in PFs over time. As such, we seek to answer the question: how to delineate the boundary of PFs (i.e. strait corridors) and recognise the importance of variations in the intensity of space-use within a PF.

This paper is outlined as follows. The background and related work in ship movement tracks analysis are introduced in Section 1. Section 2 provides a brief overview of fundamental concepts of space-us, then introduces the material of AIS and bathymetric dataset. Section 3 elaborates the proposed method for delineating PFs. Section 4 illustrates how the space-use technique performance for its application on Taiwan Strait, and shows how to utilise the proposed method to identify gaps between current routing system plan and the extracted PFs. The application is used to guide a practical discussion of the usefulness of the space-use technique for PFs analysis in Section 5. Finally, Section 6 draws the conclusion and provides some suggestions for future research applications of space-use techniques in maritime engineering.

\section{Criteria and material}

As discussed above, there are few algorithms about quantitative delineating PFs available in the scientific literature. PFs were always subjectively selected in previous routing scheme planning. In order to get a further understanding of PFs, nautical science maybe have a try to embrace other disciplines such as ecology and geography. So we develop a cross-disciplinary application of ecological methods found in habitat use of wild animal.

\subsection{Criteria related to space use}

To facilitate cross-disciplinary learning, we take a try to view PFs from the perspective of ecological discipline, especially review how habitat use is perceived in the wildlife ecology and obtain a new knowledge of PFs.

\subsubsection{The base criteria of habitat use}

Historically, animal space-use patterns have been described using a series of concepts, such as Utilisation Distribution, Home 
Range and Core Area. First let's briefly introduce some base criteria from movement ecology as below:

2.1.1.1. Utilisation distribution (UD). UD was formally defined as "the two-dimensional relative frequency distribution for the point of location of an animal over a period of time" (Winkle, 1975). Thus UD is a concept describing the intensity that an animal uses a certain geographical location in a form of probability density surface. And the intensity could be represented as "the relative amount of time that an animal spends in any place" (Seaman and Powell, 1996).

2.1.1.2. Home range. Wildlife ecology researchers believe that individual animals restrict their movements to finite areas and each wild animal has a Home Range, which defines the spatial area occupied by an individual during its day-to-day activities (Burt, 1943). Thus Home Range is a concept that attempts to describe the spatial context of an animal's behaviour and its boundaries are delineated by contour lines (i.e. isopleths) based on UD. For density based methods like Kernel Density Estimation (KDE), the 95\% Isopleths Volume (IV) of UD is accepted for delineating the boundaries of Home Range (Kernohan et al., 2001; Vander Wal and Rodgers, 2012; Zhang et al., 2013).

2.1.1.3. Core area. Seaman and Powell (1990) defined Core Area as "the core of a Home Range". Vander Wal and Rodgers (2012) further refined the definition of Core Area as "the area within which an individual spends a maximum amount of time", also proposed that there was an exponential relationship between UD volume and percentage of its corresponding Home Range, then supposed that Core Area could be "delineated using a timemaximising function derived from kernel analyses". Harris et al. (1990) concluded that core areas may be "useful in understanding the behaviour of an animal, by providing a clearer interpretation of shifting patterns of use within a home range, and allowing better insight into intra-specific and inter-specific patterns of area use".

The combination of location data and kernel Home Range estimators have produced widely accepted and intuitive interpretations of a Home Range as a probability density surface (i.e. UD), depicting the likelihood that any point in space was going to be occupied by the animal of interest at any given time (Kie et al., 2010). Although Downs et al. (2011) suggested the techniques of animal home range analysis might be useful for analyzing ships tracking data, apparently they are rarely if ever applied in maritime engineering.

\subsubsection{The derived nautical criteria}

Given the recent proliferation of AIS and satellite technologies that enable the collection of high temporal frequency ship tracking data, there is an opportunity to explore ship movements and space-use patterns. However, the ecological criteria related to space-use (e.g. Home Range, Core Area) are intended for the spatial area occupied by an individual animal. While in terms of maritime engineering, PF is a concept that attempts to describe cumulative activity patterns for ship groups. Additionally, existing analysis of Home Range or Core Area generally involve physically delineating the areas based on sample points that record an individual locations over its tracking interval (Downs et al., 2011). However those point-based techniques were not intended to handle additional information which comes with AIS tracking data (e.g. voyage relevant information). A concerted effort should be taken to identify gaps between ecological knowledge and nautical knowledge, then to integrate ecological knowledge into the quantitative approach for delineating PFs. For this reason, we develop the following novel nautical concepts which are derived from the ecological criteria.

2.1.2.1. Shipping utilisation distribution (SUD). SUD is defined as the two-dimensional relative frequency distribution for the track lines determined by waypoints from all involved ships over a period of time. Such a probabilistic space-use surface could be used to map and quantify the likelihood of strait corridors used by involved vessels group. So SUD is a concept describing the intensity that all involved ships passage certain maritime corridors.

2.1.2.2. Application nautical range (ANR). ANR is defined as the area of certain convenience for sailors with respect to navigational and hydrographical characteristics. Similar to the Home Range for an animal, ANR for sailors using given open water could be delineated as the 95\% IV from SUD. So ANR is a concept describing the maximum scope of water areas which suitable for seagoing ships.

2.1.2.3. Principal fairway (PF). PF is subjectively defined as the water areas commonly used by sailors and feature a high traffic volume, while in a quantitative view, we define PF as the area within which the cumulative sailing time for all involved ship groups reaches the maximum. PF is a concept that attempts to provide basic information about cumulative activity patterns for vessels group in a strait and serve as the basis of quantifying space-use patterns. PFs boundaries could be intersected with bathymetric-cover maps in a GIS to identify which corridors are used by seagoing merchant vessels over the course of their tracking period.

\subsection{Study area and relevant datasets}

\subsubsection{Study area and observing period}

The study area encompasses the western Taiwan Strait and offshore Fujian Province bounded by the latitudes $23^{\circ} \mathrm{N}$ and $28^{\circ} \mathrm{N}$ longitudes $116.5^{\circ} \mathrm{E}$ and $121.5^{\circ} \mathrm{E}$, as shown on Fig. 1 . The Taiwan Strait is a typical busy waterway linking Northeast Asia, Southeast Asia and the Indian Ocean rim.

The observing period took place from 1 October 2011 to 30 September 2012. Because the East Asian Monsoon has significant wind effects in the Taiwan Strait, summer in this paper is limited to

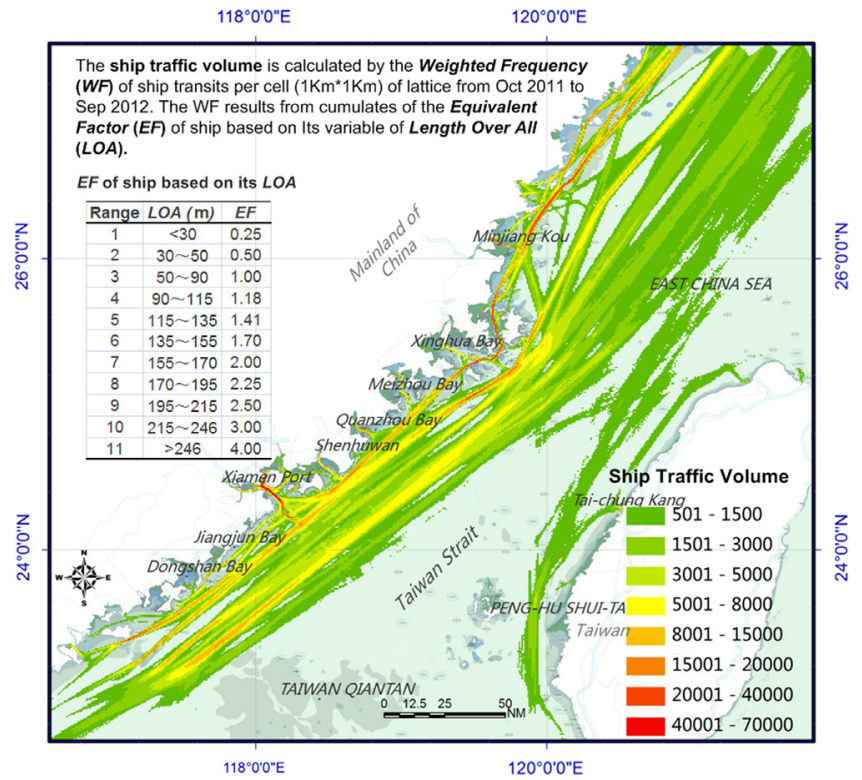

Fig. 1. Density map of merchant ship traffic in the western Taiwan Strait (from Oct 2011 to Sep 2012). 
June to August, during which the southwest monsoon occurs, while winter is bounded from November to January (Chen et al., 2013).

To make the mixed traffic volume comparable for different fairways and different temporal conditions, an Equivalent Factor $(E F)$ of individual ship based on its variable of Length Over All (LOA) was imported to calculate the mixed traffic volume. As indicated on the top-left corner of Fig. 1, a ship with its LOA between $50 \mathrm{~m}$ and $90 \mathrm{~m}$ is selected as a standard unit of $E F$, while a ship of $246 \mathrm{~m}$ LOA and upwards is represented as four standard units of $E F$. Then for each cell of cell $(1 \mathrm{~km} \times 1 \mathrm{~km})$ of lattice in study area, its variable of Weighted Frequency $(W F)$ is represented by the cumulative $E F s$ of involved transits. Then a density map of mixed traffic volume will be generated by rendering different colour for each cell with respect to its variable of $W F$.

\subsubsection{AIS tracks dataset}

The China Maritime Safety Administration (CMSA) owns a terrestrial AIS network. The original daily log files collected by this system are used to illustrate the proposed PFs extraction method. The dataset covers 39,000 vessels over a period of 12 months (from Oct 2011 to Sep 2012). The routes' aggregation was visualised and spatially analysed on ArcGIS software. A density map of merchant ship traffic flows is shown in Fig. 1, which illustrates that most commercial ships follow some strait corridors with the northeast/southwest directions.

\subsubsection{Bathymetric dataset}

The raw bathymetric data from the area studied are derived from the gridded elevation datasets on the NOAA GEODAS server with a resolution of $1^{\prime}$ (Pante and Simon-Bouhet, 2013). For the water area studied, a 300*300 bathymetric grids can be interpolated from raw bathymetric data.

\section{Method}

The proposed quantitative methods for delineating PFs follows a four-step procedure as shown on Fig. 2: converting raw AIS data to labelled route objects with clustering of waypoints in step 1; filtering out uneconomic routes with a geographic cost function in step 2; retrieving SUD with KDE in step 3; and finally constructing a statistical inference model to delineate PFs based on a nonlinear generalised regression model in step 4.

\subsection{Extracting transit-passage route}

The original ship movement datasets collected by CMSA's terrestrial AIS network were loaded into the ArcGIS Geodatabase. A 6-minute interval is used to resample these raw datasets. It is essential to divide the contiguous sequence of position reports into a set of routes. 533,800 routes were generated by using the ship route extraction method based on preliminary clustering of waypoints (Pallotta et al., 2013). The term 'route' admits multiple possible definitions. We interpret it here to mean a sequence of position reports from a particular ship, without significant time gaps, which show some level of purposeful motion. For the observing period of 12 months, there are 35,500 transit-passage routes objects. Here transit-passage means involved ship undertakes a continuous and expeditious transit of the Taiwan Strait. Only the transit-passage route objects in summer/winter are used for PFs analysis. We are working on the assumption that those transit-passage ships exclude the handy-size individuals. Thus, 15,200 transit-passage ones are selected as route samples as shown on Table 1.

\subsection{Filtering out uneconomic routes}

To minimise the uncertainty caused by anomalous tracks and filter out the noisy routes objects with unnecessary sharp turns or twists, we formulated a geographic cost function to evaluate route object's economic performance. It is a common sense that a seaman generally chooses a route with the shortest distance (i.e. Least Geographic Cost). From the perspective of Geographic Information Science, given a specified route of Origin-Destination, the unique Least Cost Path (LCP) can be theoretically generated using the corresponding OriginDestination points. There are various numerical cell-based methods used to calculate LCP constrained by bathymetric and topographic

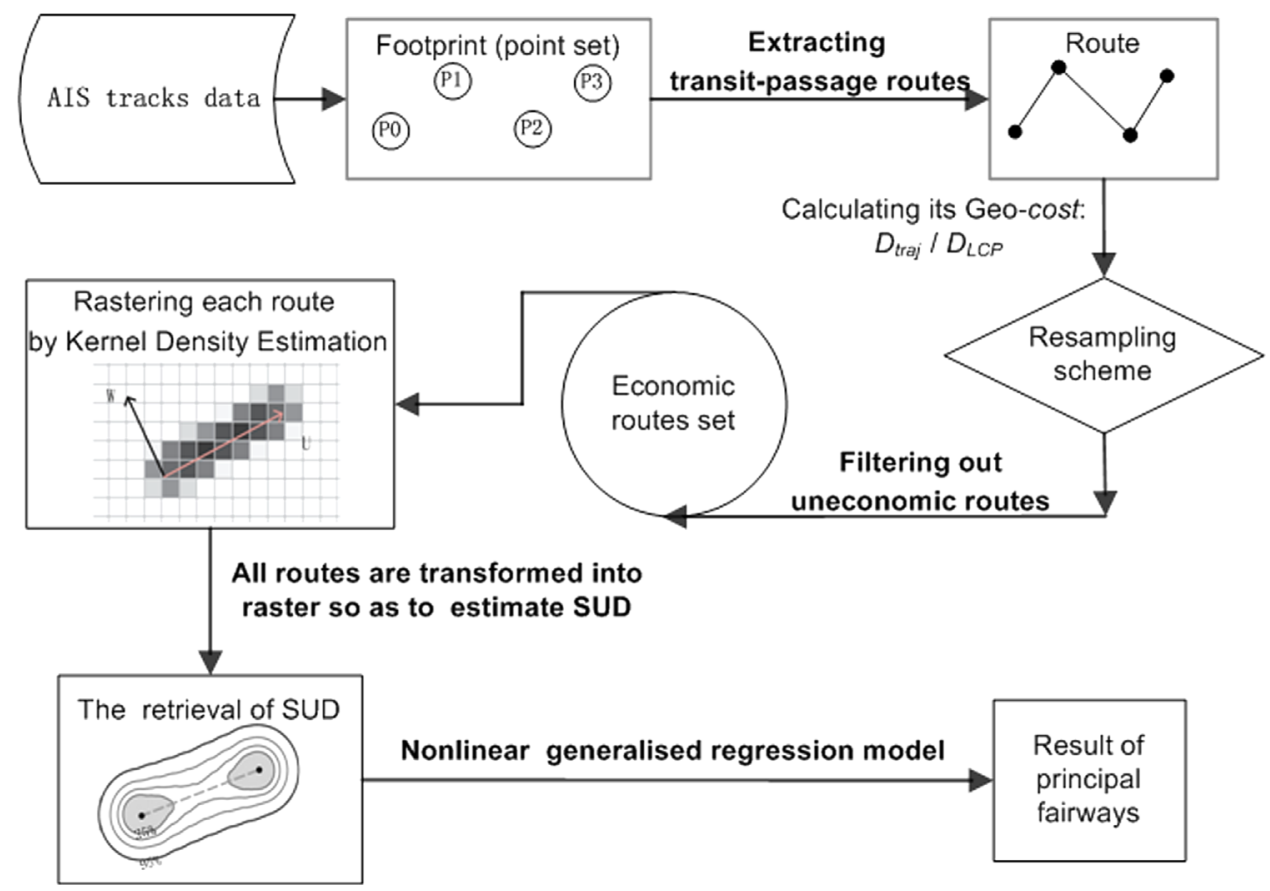

Fig. 2. The workflow of quantitative method for delineating PFs with a four-step procedure. 
Table 1

Components of transit-passage route samples group by season and direction.

\begin{tabular}{ll}
\hline Season/direction & Subset number \\
\hline Winter/northbound & 2728 \\
Summer/northbound & 4040 \\
Winter/southbound & 3675 \\
Summer/southbound & 4795 \\
\hline
\end{tabular}

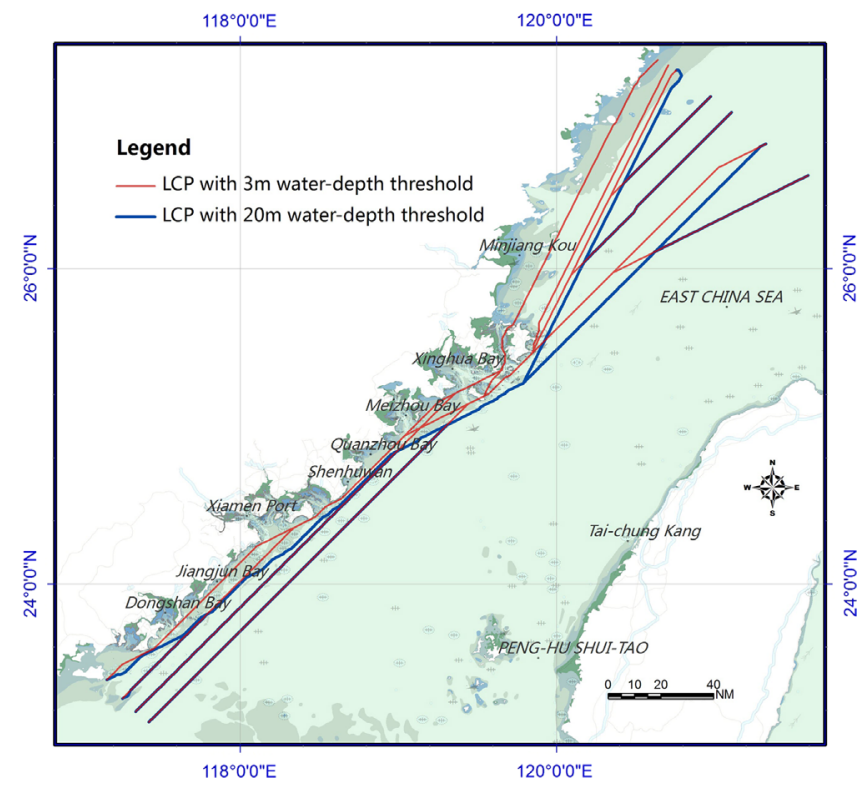

Fig. 3. Theoretical LCP cases in the western Taiwan Strait.

obstacles (Appice et al., 2013; Pante and Simon-Bouhet, 2013; Ray, 2005; Tsatcha et al., 2014).

Given the minimum water depth, $D e p_{\min }$, we can establish a Transition Matrix with $n^{2 *} n^{2}$ elements (for the case of Taiwan Strait, $n=300$ ) containing the probability of transition from one cell of the Bathymetric Grid to adjacent cells (Pante and SimonBouhet, 2013). The running time complexity of generating the Transition Matrix is $o\left(n^{2}\right)$, and a reasonable value of $n$ to define Bathymetric Grid should be carefully selected. Based on a specific Transition Matrix, the shortest great-circle distance between pairs of Origin-Destination sites, avoiding bathymetric and topographic obstacles, can be calculated, which is noted as $D_{\mathrm{LCP}}$. For the case of the Taiwan Strait, Fig. 3 depicts the corresponding theoretical LCP of typical routes predefined by certain Origin-Destination under the condition of water-depth threshold (i.e. $D e p_{\min }=3 \mathrm{~m}$ and $D e p_{\min }=20 \mathrm{~m}$ ). Theoretical LCP research in the northern part of the study aligns with the real ship traffic density map (Fig. 2) better than the southern the other part does. This discrepancy occurs because seamen prefer the route with less turning waypoints. In this paper, the theoretical LCP with a $20-\mathrm{m}$ water-depth threshold is used as the benchmark for evaluating the geographic cost of route, because this research is intend to identify strait corridors in open water.

A simple geographic cost function of route can be developed as follows:

Cost $=D_{\text {traj }} / D_{\text {LCP }}$

where $D_{\text {traj }}$ is the real length of the specified route $D_{\text {LCP }}$ defined by the corresponding Origin-Destination sites.

Because there are many transits of ships sharing the same Origin-Destination elements from Transition Matrix, the efficiency
Table2

Distribution of transit samples' geo-cost grouped by direction and season.

\begin{tabular}{lllll}
\hline Season/direction & $\begin{array}{l}\text { 1st } \\
\text { Quartile }\end{array}$ & $\begin{array}{l}\text { 2nd } \\
\text { Quartile }\end{array}$ & $\begin{array}{l}\text { 3rd } \\
\text { Quartile }\end{array}$ & $\begin{array}{l}\text { Standard } \\
\text { deviation }\end{array}$ \\
\hline Winter/northbound & 1.001 & 1.006 & 1.012 & 0.012 \\
Summer/northbound & 0.997 & 1.002 & 1.008 & 0.012 \\
Winter/southbound & 0.997 & 1.001 & 1.006 & 0.008 \\
Summer/southbound & 0.997 & 1.002 & 1.008 & 0.008 \\
\hline
\end{tabular}

of algorithm for computing Formula (1) can be improved by setting a cache of the adjacency matrix of Origin-Destination. By calculating the Cost of each route object, the uneconomic routes can be identified by tuning a reasonable threshold of Cost.

The uneconomic routes are filtered using Formula (1). Table 2 shows the statistics for the 15,200 transit samples' Geographic Cost to highlight the economic performance of routes in different seasons: First, the Standard Deviation $(S D)$ of northbound traffic was larger than that of southbound traffic for the dispersion of geo-cost for opposing streams of traffic; Second, the economic performance of northbound traffic during the winter was the worst, and that of southbound traffic during the winter was the best. These variables demonstrate that a seasonal effect is significant for opposing streams of traffic, especially in the northbound direction. Such a seasonal effect may be attributed to the fact that the northeast monsoon during winter is stronger than that of the southwest monsoon in summer.

To examine route samples ranked by geo-cost, we used winter values and conducted a spatial correlation analysis of seasonal differences and similarities with ArcGIS software. The analysis resulted in the division of the spatial features of route subsets by quartile from the ranked set of geo-cost. Fig. 4 shows selected route objects with respect to the top and bottom $5 \%$ of geo-cost.

The worst economic subset with sharp turns or twists is in the set of geo-costs of the 3rd quartile or above. Most of the turns or twists from the subset occurred in the northern region of the research area, as shown on Fig. 4(left). Thus, an uneconomic route subset should be filtered out. The other subsets depicted in Fig. 4 (right) were selected as clean routes for delineating the principal fairways.

\subsection{KDE estimator for the retrieval of SUD}

Based on the lined-based kernel density estimator for the retrieval of UD from animal movement tracks (Steiniger and Hunter, 2013), we applied KDE to estimate the SUD of transitpassage routes. The KDE method begins by centring a bivariate probability function with unit volume, namely a kernel, over each route. A regular grid with a user-defined cell size is then superimposed on route samples. Each line segment $l_{i, i+1}$ (where $i=1, \ldots$, $n$ are route-waypoints) of route samples is rasterised individually, and the raster $r_{i, i+1}$ is calculated using the KDE. A probability density estimate is calculated at each grid-cell by summing the overlapping volumes. A two-dimensional probability surface over the entire grid is then generated. Thus the retrieval of SUD is represented by a grid of regular cells so as to measure the hard boundary delineating the edge of polygon containing the area used by transit-passage routes. Namely, the isopleths from SUD delineate different portions of Application Nautical Range (ANR) volumes, as shown on Fig. 5.

\subsection{Nonlinear generalised regression model for PFs}

Similar to the individual-based quantitative model for delineating Core Area of animal space use (Seaman and Powell, 1996; Vander 

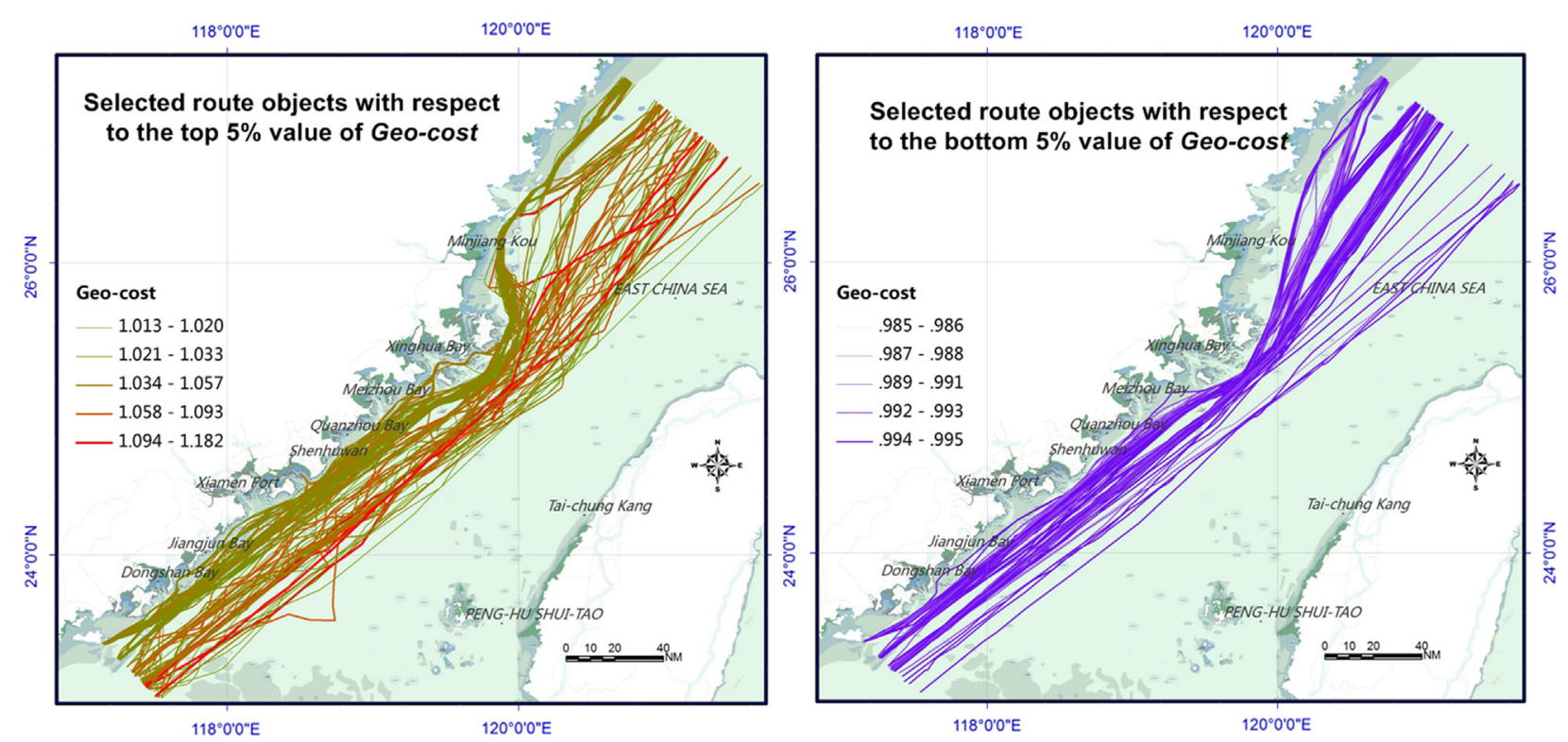

Fig. 4. Comparison of spatial distributions of selected routes with respect to the top (left) and bottom (right) $5 \%$ of the geo-cost.

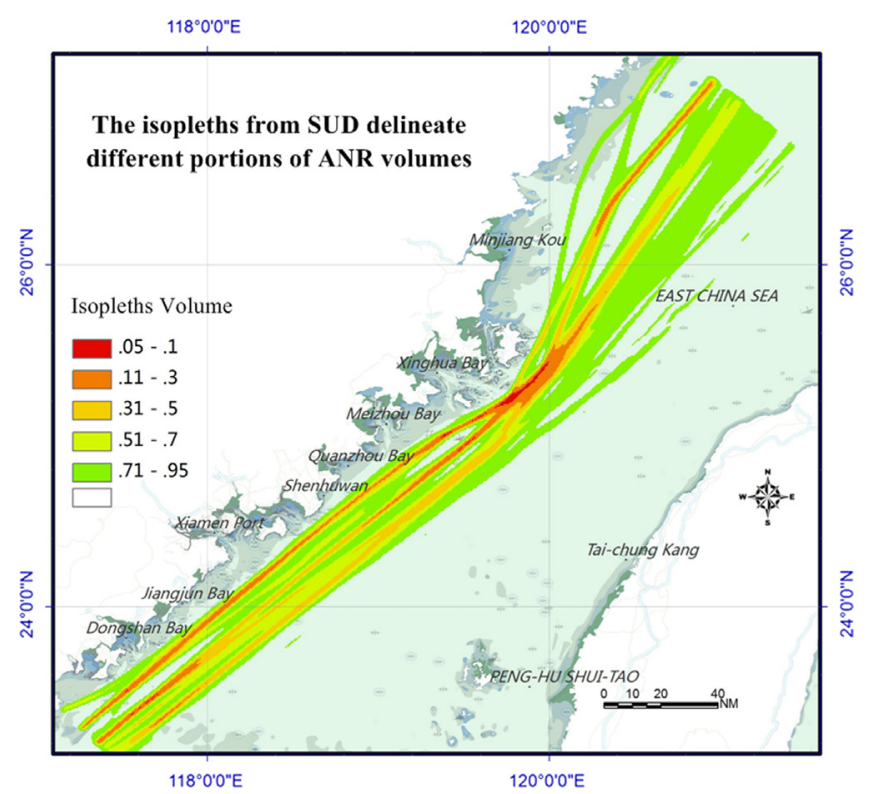

Fig. 5. The isopleths from SUD delineate different portions of ANR volumes.

Wal and Rodgers, 2012), an exponential curve of SUD could be drafted by a statistical inference approach (i.e. Nonlinear generalised regression model), as shown on the left side of Fig. 6. The SUD area is the coverage of the involved ships' Utilisation Distribution, shown on the right side of Fig. 6. In other words, given a certain IV of $p$ from SUD, there is a Specific Nautical Range (SNR) representing a unique portion of ANR. So the $I V$ is indicative of the likelihood of the cumulative sailing time for all involved ships in ANR: the greater the volume, the more cumulative sailing time spent. The curve in the left side Fig. 6 is to interpret the relationship between the $I V$ (represented in the $x$-axe) and the area of its corresponding SNR. For the sake of congruent axes, the area of SNR is standardised proportional to the total area covered by the Application Nautical Range (ANR) and displayed as a percentage, which is called Percent SNR Area. Especially, the $I V$ of $p=0.95$ is selected to delineate the ANR. The ratio is obtained as below:

$R_{\mathrm{psa}}=S_{p} / S_{0.95}$ where $R_{\mathrm{psa}}$ is the Percent SNR Area, $S_{0.95}$ is the area of ANR and $S_{p}$ is the area of SNR.

Because SUD is estimated by KDE, the relationship between $p$ and $R_{\mathrm{psa}}$ fits an Exponential Regression (ER) equation as below:

$R_{\mathrm{psa}}=a * e^{b * p}+c$

where $a$ is the $y$-intercept, $b$ is the constant of the ER equation, and $c$ is the surplus constant. $a, b$ and $c$ can be calculated using statistical inference procedures.

Vander Wal and Rodgers (2012) revealed that there is a unique point at which the slope is equal to 1 that can be found in the monotonically increasing and asymptotically fitted ER curve by differentiation. The superficial mathematical meaning of the unique point is that $R_{\text {psa }}$ begins to increase more rapidly than $I V$. Additionally, there is an underlying nautical significance that the involved ships' sailing time spent in the SNR are maximised relative to their movement on ANR. Therefore, the explicit empirical threshold for delineating PFs can be obtained as below:

Calculate the first derivative of the ER curve and assign the slope of the curve equation a value of 1 :

$\frac{\partial R_{\mathrm{psa}}}{\partial p}=a * b * e^{b * p}=1$

A unique $P_{\mathrm{pf}}$, which determines the contour of PFs, can be solved as follows:

$P_{\mathrm{pf}}=\frac{-\ln (a * b)}{b}$

The more closely the result approaches zero, the stronger the spatial heterogeneity of the related sample becomes, which means the corresponding PF is used more heavily.

\section{Application}

4.1. Examining the directional and seasonal factor for Taiwan Strait's PFs

In order to highlight the seasonal variation between opposing streams of traffic in the western Taiwan Strait, the PFs of ship traffic are extracted from the cleaned routes with the proposed algorithm. Table 3 shows the confidence intervals for the two parameters (i.e. $a, b)$ in the Exponential Regression Model and $I V$, 


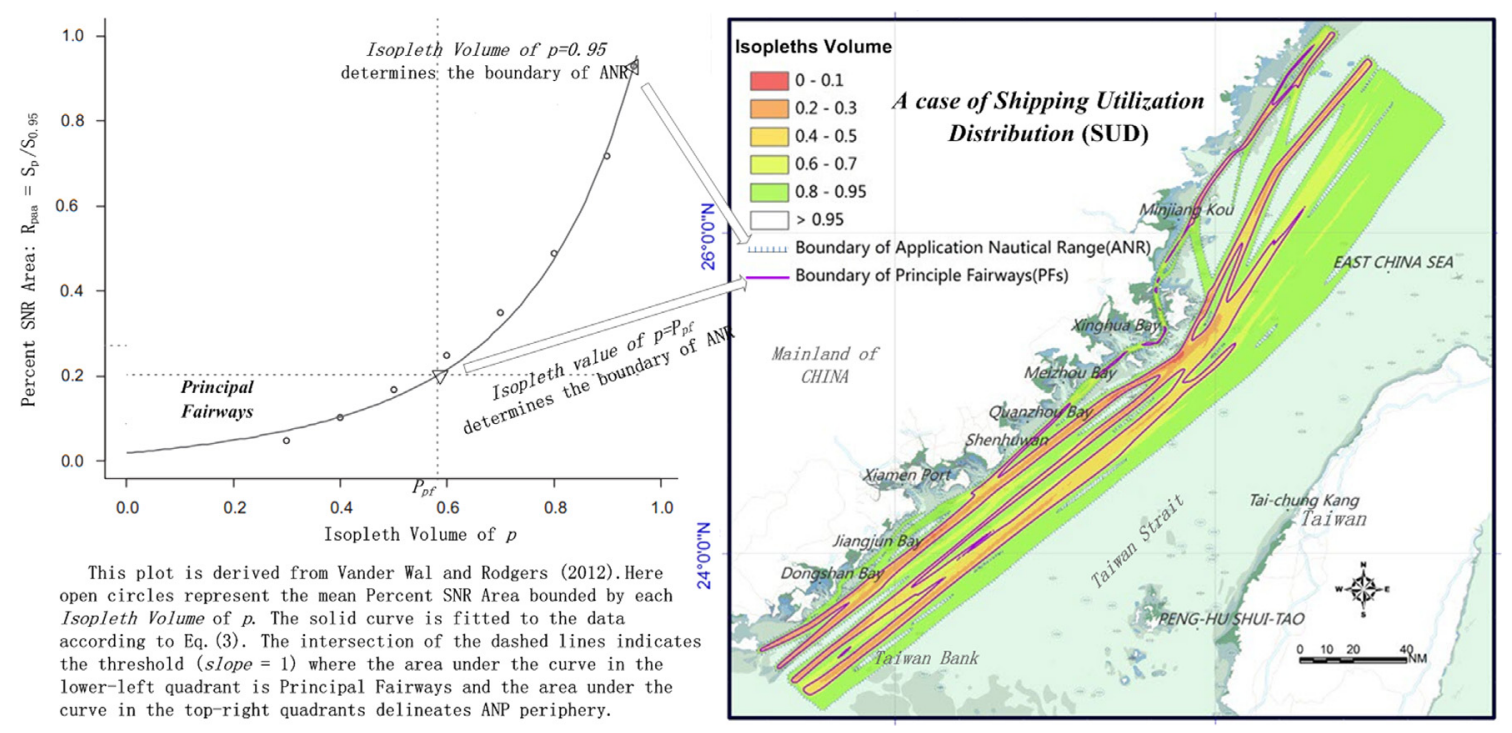

Fig. 6. A nonlinear generalised regression method to delineate PFs.

Table 3

Regression results of the extracted PFs in the western Taiwan Strait (Grouped by season and direction).

\begin{tabular}{|c|c|c|c|c|c|c|c|c|c|}
\hline \multirow[t]{2}{*}{ Season/direction } & \multicolumn{3}{|l|}{$a$} & \multicolumn{3}{|l|}{$b$} & \multicolumn{3}{|c|}{$P_{p f}=-\ln \left(a^{*} b\right) / b$} \\
\hline & $2.5 \%$ & $97.50 \%$ & LCE & $2.5 \%$ & $97.50 \%$ & LCE & $2.5 \%$ & $97.50 \%$ & LCE \\
\hline Winter/southbound & 0.019 & 0.024 & 0.022 & 3.71 & 3.915 & 3.812 & 0.709 & 0.607 & 0.656 \\
\hline Winter/northbound & 0.093 & 0.105 & 0.099 & 2.465 & 2.579 & 2.521 & 0.597 & 0.508 & 0.551 \\
\hline Summer/southbound & 0.038 & 0.044 & 0.041 & 3.269 & 3.418 & 3.343 & 0.639 & 0.556 & 0.596 \\
\hline Summer/northbound & 0.044 & 0.051 & 0.048 & 3.165 & 3.307 & 3.236 & 0.62 & 0.539 & 0.578 \\
\hline
\end{tabular}

designating the PFs for each group route subset divided by the direction and season. The results indicate that each subset's IV reasonably fits the exponential curve.

The minimum and maximum $I V$ among the subsets occurred in winter. The PFs of northbound traffic flow in winter shows the strongest convergence, but that of southbound traffic is the most spatially homogeneous. The result shows that the spatial heterogeneity of the PFs is stronger for northbound vessels than southbound ones both in winter and summer. And southbound traffic is more convergent in summer than in winter, whereas northbound traffic shows the opposite trend. To achieve a more accurate assessment of spatiotemporal characteristics for opposing traffic streams. We used ArcGIS to visualise each boundary of the PFs associated with the $I V$ items listed in Table 3. The result shown in Fig. 7, presents the extracted principal fairways crossing the Taiwan Strait in northeast/southwest directions. It shows that an extra strait-corridor in offshore regions is used for northbound traffic in winter besides the other commonly used sea-lanes.

\subsection{Identifying gaps between the extracted PFs and current routing system plan}

To Identify gaps between the extracted PFs and current routing system plan, a comparison is made with the China's Coastal Ships Routing System Plan (CCSRSP) issued by CMSA (2011). The current ship routing system plan in the western Taiwan Strait involves recommended coastal routes, Precautionary Areas (PAs) and TSSs on open sea, as shown on Fig. 8. Recommended coastal routes of CCSRSP are intended for handy-size vessels conducting short sea shipping trips. Precautionary areas (PAs) are specific zones where ships must keep cautious because of frequent crossing traffic. Opposing streams of traffic using open sea routes are managed and controlled by the TSS, which is generally composed of a separation zone, borderline and traffic lane. Because there is an extra corridor in offshore regions derived from the northboundwinter PFs, the layer of CCSRSP is then superimposed on the PFs as shown on Fig. 8.

Visual comparisons reveal that the validity of our proposed method to a certain degree: first, the offshore regions of the northbound-winter PFs confirm to separation zones of No.4-6 TSSs derived from CCSRSP. Second, the coastal regions of the northboundwinter PFs confirm recommended southbound coastal routes derived from CCSRSP on the south side of Niushan Light (navigation aids).

Furthermore, Fig. 8 also shows the following two gaps between cumulative activity patterns of transit passage ships and current CCSRSP. The first is that the lines linking current No. 2-3 PAs and corresponding TSSs (i.e. No. 1-3 TSSs) deviate from the axis-lines of the extracted PFs. A concerted effort should be taken to further refined routing system of the strait. The second gap lies in that existing recommended coastal routes wriggle their way in an ' $S$ ' shape. There are so many sharp turns or twists that they are unsuitable for merchant ships to pass the strait efficiently. This indicates that new routes should be recommended to supplement the current CCSRSP and some PAs.

\section{Discussion}

Methods of Home Range or Core Area are routinely applied to analyse movement of wildlife, while the techniques are equally applicable for ship movement tracks. Although the idea of the nonlinear generalised regression approach for delineating core areas of animal space use was already introduced by Vander Wal and Rodgers (2012), and the line-based KDE for the retrieval of UD 
$118^{\circ} 0^{\prime} 0^{\prime \prime} \mathrm{E}$
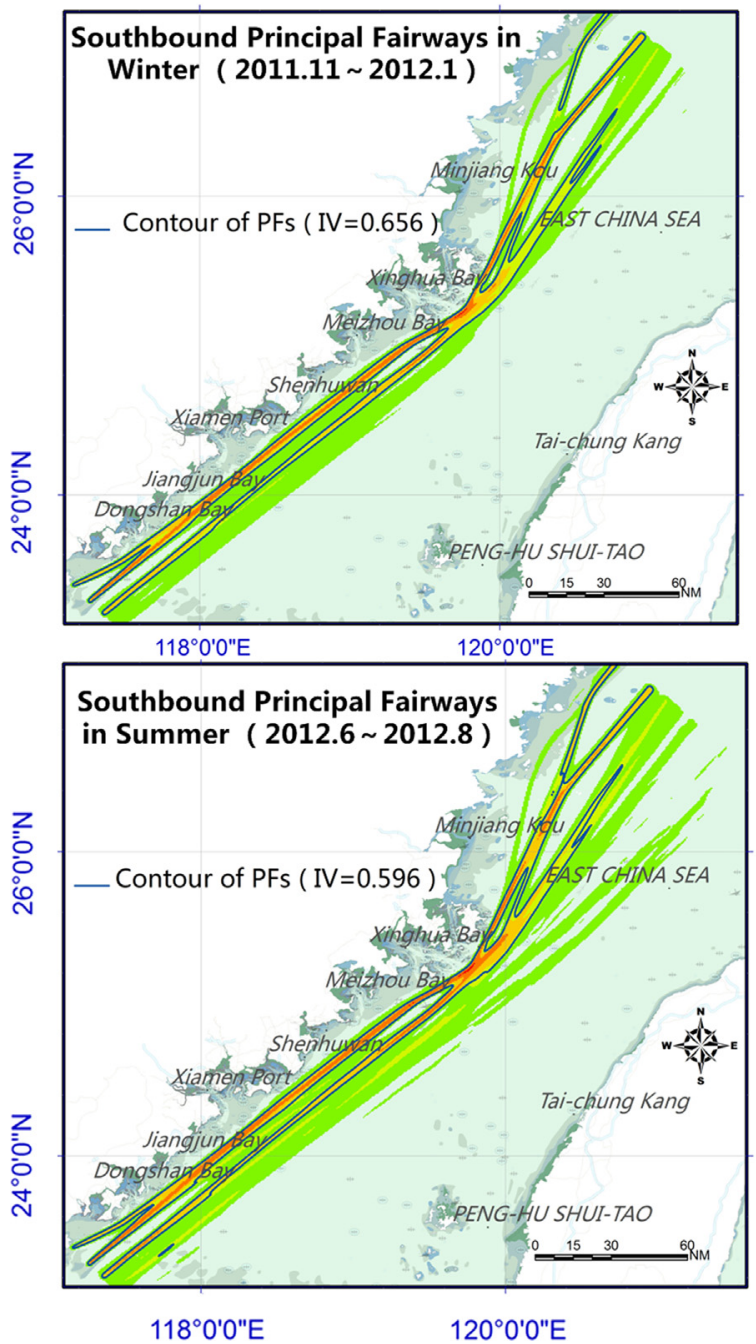

$118^{\circ} 0^{\prime} 0^{\prime \prime} \mathrm{E}$

$120^{\circ} 0^{\prime} 0^{\prime \prime} \mathrm{E}$
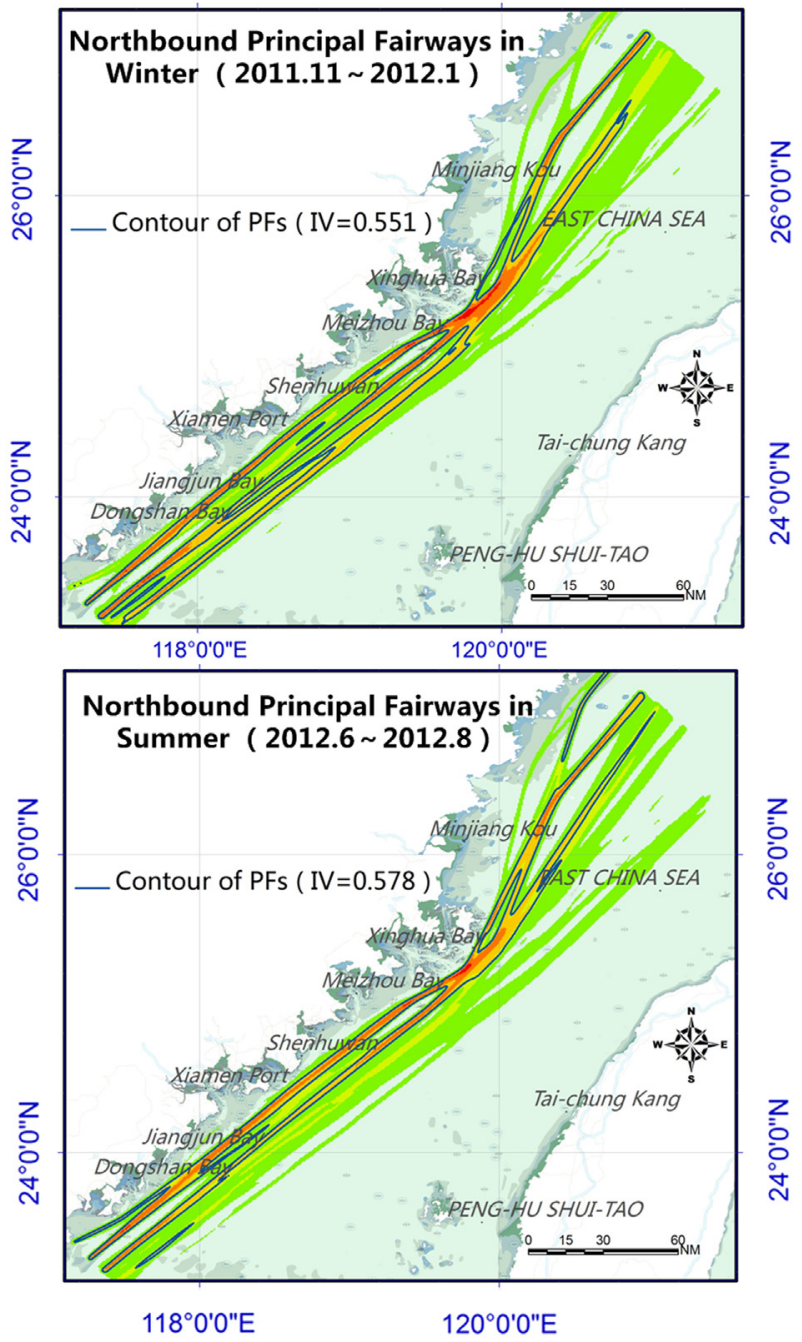

Isopleths Volume

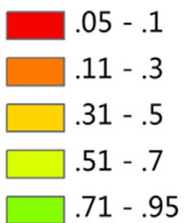

Fig. 7. Economic voyages' PFs in the western Taiwan Strait by direction and season.

$118^{\circ} 0^{\circ} 0^{\prime \prime} \mathrm{E}$

$120^{\circ} 0^{\circ} 0^{\prime \prime} \mathrm{E}$

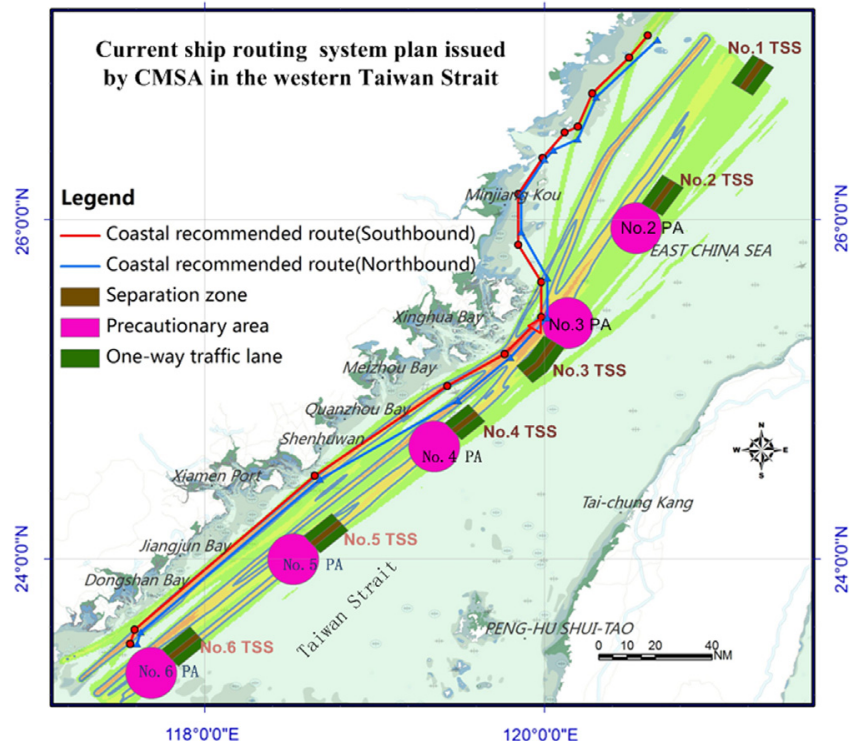

Fig. 8. Current ship routing system plan issued by CMSA in western Taiwan Strait. from animal movement tracks was proposed by Steiniger and Hunter (2013), the quantitative approach for delineating PFs presented in this manuscript makes a number of potentially important contributions in the field of maritime engineering.

First, the nonlinear generalised regression model for delineating PFs provides a rigorous mathematical framework for accurately modelling maritime corridors than cluster-based counterpart (Aarsæther and Moan, 2009; Arguedas et al., 2014a,b; Pallotta et al., 2013; Santos et al., 2012), as it increases understanding PFs boundaries; In the case of the Taiwan Strait, this research shows a superior ability to delineate strait corridors commonly used by transit-passage merchant ships. Meanwhile, when coupled with current routing system plan, PFs boundaries can be useful to identify gaps between current TSSs and cumulative activity patterns for vessels group derived from real AIS tracks. Such gaps play important roles in giving valuable guidelines and advise of further refined ship routing system in the Taiwan Strait.

Second, the line-based KDE method for geo-visualising changes of shipping space-use patterns over time is also useful. Not only is it easy to implement in existing GIS software packages (e.g. ArcGIS), but geo-visualising shipping space-use patterns under different conditions (e.g. season, direction) are also helpful to view the effect of seasonal and directional factors for maritime corridors. There is 
no information about the temporal dimension of strait corridors and space-use patterns for traditional TSS analysis (Aydogdu et al., 2012; Johnson, 1973; Szlapczynski, 2013). While our proposed method is useful not only for mapping the total area (i.e. Application Nautical Range) over the whole observing period, but also for exploring the changes of most intense regions used by involved vessels over a broad time period such as season. In the case of the Taiwan Strait, the probability surface identifies where and when different corridors are used by transit-passage vessels, as well as how those patterns changed over season.

While the proposed quantitative space-use method may offer an innovative framework for strait corridors identification from mass ship movement tracks, there are several practical considerations worth noting. The resulting probabilistic space-use surfaces are sensitive to sampling scheme. This research is intend to delineate PFs of ship passages through a strait and explore changes of PFs over season, thus a preliminary clearing and clustering method are applied to select economic transit-passage routes objects in the period of winter and summer. Such sampling scheme is specified based on prior knowledge (e.g. East Asian Monsoon in the Taiwan Strait). Second, depending on the number of routes derived from ship tracking points, geographical extent of the dataset, and the desired spatial resolution, computing the probabilistic space-use surfaces can be computationally intensive simply because of the large number of kernels required. In this study, spatial resolution was chosen that were smaller than the commonly accepted fairway-width (i.e. 6 nautical miles) for associated open water.

\section{Conclusion}

The strait environment remains an open space leads to significant uncertainty in the definition of principal fairways. In this paper, Space-use method, which is available and popular in movement ecology, is adopted to the problem of strait PFs analysis. We put forward a series of novel nautical concepts which are derived from fundamental concepts of space-use in animal ecology, then developed a cross-disciplinary quantitative approach for delineating PFs and validates it with a case study around western Taiwan Strait.

The novelty of PFs concept developed in this paper lies in: it provide basic information about cumulative activity patterns for vessels group in a strait and serve as the basis of quantifying space-use patterns. Based on the rigorous mathematical framework for accurately modelling for Home Range and Core Area, our proposed quantitative approach produces an intuitive interpretation of PFs as a continuous probability density surface (i.e. SUD).

The advantages of the proposed method lie in: First, it provides a rigorous mathematical framework for documenting and analyzing principal fairways boundaries, which could be intersected with bathymetric-cover maps in a GIS. This is useful to identify when and where strait corridors are used by transit-passage vessels, so as to facilitate a more detailed analysis of PFs than existing counterpart. Second, probabilistic space-use surface can be used to map and quantify the likelihood of strait corridors used by transit-passage vessels at specific sailing-direction at given season (e.g. winter or summer), which provide a novel way to geovisualise ship movement over time.

It is arguable for our proposed prototype of geographic cost function which was applied to filter out noisy routes. The essential factors for calculating the cost of route depend on what a noisy route means. A route with unnecessary sharp turns or twists is defined as a noise dataset in this paper. Thus only the variable of distance is taken into consideration in current prototype of geographic cost function. When the definition of a noisy route is based on its fuel consumption, the situation will be more complex. Besides the above factor of distance, another essential oceanographic variables, such as the speed of ship, surface oceanic current/wind field, should be considered to formulate an ideal cost function of route based on its fuel consumption in further research.

There is a proliferation of new satellite based AIS receivers that lead to improve ship tracking data. Our proposed approach can be potentially utilised for numerous studies in maritime transport engineering to answer a broad array of questions. It is argued the proposed method has certain value in maritime risk assessment and waterway planning in a specific strait. Although this research open new avenues in the strait-TSS analysis, our knowledge of why seagoing ships use strait corridors in the ways we observe will only advance by researchers using next generation of nautical traffic model. In order to explore new and innovative questions about the empirical space-use patterns of involved vessels group, the essential conditions of meteorological and oceanographic data (e.g. wind, wave, current) are necessary so as to get a thorough understanding of PFs in future study.

\section{Acknowledgments}

This study was supported by National High Technology Research and Development Program of China(863 Program, no. 2012AA12A211) and Fundamental Applied Research Program by Ministry of Transport of China (no. 2013329815290). This work was also partially supported by LREIS Foundation (088RA500KA) and Scientific Research Foundation of Jimei University (no. ZC2014005). The authors are grateful for their financial support. The authors acknowledge four anonymous reviewers for their valuable and detailed comments. The authors also thank Liang HE, Ruishan HU and Jiawei YI from Institute of Geographic Sciences and Natural Resources Research, Chinese Academy of Sciences for their helpful advice. Special thanks are given to Sir. Lu Xiang, the director of Xiamen Navigation Aids Department of Donghai Navigation Safety Administration (DNSA), in providing ships movement tracks.

\section{References}

Aarsæther, K.G., Moan, T., 2009. Estimating navigation patterns from AIS. J. Navig 62 (04), 587-607.

Appice, A., Malerba, D., Lanza, A., 2013. Using geographic cost functions to discover vessel itineraries from AIS messages. In: Atzmueller, M., Chin, A., Helic, D. Hotho, A. (Eds.), Ubiquitous Social Media Analysis. Springer, Berlin Heidelberg, pp. 44-62.

Arguedas, V.F., Pallotta, G., Vespe, M., 2014a. Automatic generation of geographical networks for maritime traffic surveillance. In: IEEE 17th International Conference on Information Fusion (FUSION), Salamanca, pp. 1-8.

Arguedas, V.F., Pallotta, G., Vespe, M., 2014b. Unsupervised maritime pattern analysis to enhance contextual awareness. In: Proceedings of the First International Workshop on Context-Awareness in Geographic Information Services (in conjunction with GIScience 2014). CAGIS 2014, Wien, Austria, pp. 50-61.

Asmara, I.P.S., Kobayashi, E., Artana, K.B., Masroeri, A.A., Wakabayashi, N., 2014 Simulation- based estimation of collision risk during ship maneuvering in twolane canal using mathematical maneuvering group model and automatic identification system data. In: 33rd International Conference on Ocean, Offshore and Arctic Engineering (OMAE2014), Proceedings of the ASME 2014, CA USA.

Aydogdu, Y.V., Yurtoren, C., Park, J.S., Park, Y.S., 2012. A study on local traffic management to improve marine traffic safety in the Istanbul Strait. J. Navig. 65 (1), 99-112.

Blokus-Roszkowska, A., Smolarek, L., 2012. Collision risk estimation for motorways of the sea. Reliab.: Theory Appl. 1 (2), 58-68.

Burt, W.H., 1943. Territoriality and home range concepts as applied to mammals. Journal of Mammalogy. 24 (3), 346-352.

CMSA, 2011. The General Planning of China Coastal Ships Routeing, No. 388 Officia Document issued by China Ministry of Transport, on July 26th, 2011

Chen, C., LEE, C., Chen, C., Tseng, C. 2013. The integration of nautical hazard assessment and harbor GIS models to the Taichung Port area in Taiwan. Nat. Hazards 67 (2), 275-294.

Christiansen, M., Fagerholt, K., Nygreen, B., Ronen, D., 2013. Ship routing and scheduling in the new millennium. Eur. J. Oper. Res. 228 (3), 467-483. 
van Dorp, J.R., Merrick, J.R.W., 2011. On a risk management analysis of oil spill risk using maritime transportation system simulation. Ann. Oper. Res. 187 (1), 249-277.

Downs, J.A., Horner, M.W., Tucker, A.D., 2011. Time-geographic density estimation for home range analysis. Ann. GIS 17 (3), 163-171.

Fowler, T.G., Sørgård, E., 2000. Modeling ship transportation risk. Risk Anal. 20 (2) 225-244.

Fujii, Y., Shiobara, R., 1971. The analysis of traffic accidents. J. Navig. 24 (04) $534-543$.

Goerlandt, F., Kujala, P., 2011. Traffic simulation based ship collision probability modeling. Reliab. Eng. Syst. Saf. 96 (1), 91-107.

Goerlandt, F., Kujala, P., 2014. On the reliability and validity of ship-ship collision risk analysis in light of different perspectives on risk. Saf. Sci. 62, 348-365. http: //dx.doi.org/10.1016/j.ssci.2013.09.010.

Goerlandt, F., Ståhlberg, K., Kujala, P., 2012. Influence of impact scenario models on collision risk analysis. Ocean Eng. 47 (6), 74-87.

Goodwin, E.M., 1975. A statistical study of ship domains. J. Navig. 28 (3), 329-341.

Guillarme, N.L., Lerouvreur, X., 2013. Unsupervised extraction of knowledge from SAIS data for maritime situational awareness. In: 16th International Conference on Information Fusion, Istanbul, pp. 2025-2032.

Halpern, B.S., Walbridge, S., Selkoe, K.A., Kappel, C.V., Micheli, F., D’Agrosa, C., Bruno, J.F., Casey, K.S., Ebert, C., Fox, H.E., Fujita, R., Heinemann, D., Lenihan, H.S., Madin, E.M.P., Perry, M.T., Selig, E.R., Spalding, M., Steneck, R., Watson, R., 2008. Supporting online material for "A global map of human impact on marine ecosystems". Science 319 (5865), 948-952.

Hansen, M.G., Jensen, T.K., Lehn-Schiøler, T., Melchild, K., Rasmussen, F.M., Ennemark, F., 2013. Empirical ship domain based on AIS data. J. Navig. 6 (66), 931-940.

Harris, S., Cresswell, W.J., Woollard, T., Wray, S., 1990. Home-range analysis using radiotracking data: A review of problems and techniques particularly as applied to the study of mammals. Mammal Rev. 20, 97-123.

IMO, 2003. MSC/Circ.1060: Guidance Note on the Preparation of Proposals on Ships' Routeing Systems and Ship Reporting Systems. 〈http://tinyurl.com MSC-Circ-1060〉.

Jensen, T.K., Hansen, M.G., Lehn-Schioler, T., Melchild, K., Rasmussen, F.M., Ennemark, F., 2013. Free flow-efficiency of a one-way traffic lane between two pylons. J. Navig. 66 (6), 941-951.

Johnson, D.R., 1973. Traffic in the English channel and Dover Strait: I-Traffic surveys. J. Navig.. 26 (01), 75-92.

Kaluza, P., Kolzsch, A., Gastner, M.T., Blasius, B., 2010. The complex network of global cargo ship movements. J. R. Soc. Interface 7 (48), 1093-1103.

Kernohan, B.J., Gitzen, R.A., Millspaugh, J.J., 2001. Analysis of animal space use and movements Chapter 5. Marzluff, J.J.M.M. (Ed.), Radio Tracking and Animal Populations. Academic Press, San Diego, CA, pp. 125-166. http://dx.doi.org 10.1016/B978-012497781-5/50006-2.

Kie, J.G., Matthiopoulos, J., Fieberg, J., Powell, R.A., Cagnacci, F., Mitchell, M.S., Gaillard, J.-M., Moorcroft, P.R., 2010. The home-range concept: are traditional estimators still relevant with modern telemetry technology? Philos. Trans. R Soc. B: Biol. Sci. 365 (1550), 2221-2231.

Klanac, A., Duletić, T., Erceg, S., Ehlers, S., Frank, D., 2010. Environmental risk of collisions in the enclosed European waters: Gulf of Finland, Northern Adriatic and the implications for tanker design. 5th Intl. Conference on Collision and Grounding of Ships, Espoo, Finland, pp. 55-65.

Können, G.P., Koek, F.B., 2005. Description of the Cliwoc database. Clim. Change 73 (1-2) 117-130.

Li, S., Meng, Q., Qu, X., 2012. An overview of maritime waterway quantitative risk assessment models. Risk Anal. 32 (3), 496-512.

Long, J.A., Nelson, T.A., 2012. A review of quantitative methods for movement data. Int. J. Geogr. Inf. Sci. 27 (2), 292-318.

Montewka, J., Goerlandt, F., Kujala, P., 2012. Determination of collision criteria and causation factors appropriate to a model for estimating the probability of maritime accidents. Ocean Eng. 40, 50-61. http://dx.doi.org/10.1016/j. oceaneng.2011.12.006.

Montewka, J., Ehlers, S., Goerlandt, F., Hinz, T., Tabri, K., Kujala, P., 2014. A framework for risk assessment for maritime transportation systems-a case study for open sea collisions involving RoPax vessels. Reliab. Eng. Syst. Saf. 124 $142-157$.

Oltmann, J.-H., 2014. Route topology modelling as a potential means to reconcile marine spatial planning with demands of the Sea Traffic-the North Sea Example. In: 18th IALA Conference, A Coruña, Spain. 〈http://tinyurl.com/ 2014-IALA-report>.
Otto, S., Pedersen, P.T., Samuelides, M., Sames, P.C., 2002. Elements of risk analysis for collision and grounding of a RoRo passenger ferry. Mar. Struct. 15 (4-5), 461-474.

Pallotta, G., Vespe, M., Bryan, K., 2013. Vessel pattern knowledge discovery from AIS data: a framework for anomaly detection and route prediction. Entropy 15 (6), 2218-2245.

Pallotta, G., Horn, S., Braca, P., Bryan, K., 2014. Context-enhanced vessel prediction based on Ornstein-Uhlenbeck processes using historical AIS traffic patterns: real-world experimental results. In: 17th International Conference on Information Fusion (FUSION), Salamanca, pp. 1-7.

Pante, E., Simon-Bouhet, B., 2013. marmap: a package for importing, plotting and analyzing bathymetric and topographic data in R. PLoS ONE 8 (9), e73051. http: //dx.doi.org/10.1371/journal.pone.0073051.

Qu, X., Meng, Q., Li, S.Y., 2011. Ship collision risk assessment for the Singapore Strait. Accid. Anal. Prev. 43 (6), 2030-2036.

Ray, N., 2005. Pathmatrix: a geographical information system tool to compute effective distances among samples. Molecular Ecology Notes 5 (1), 177-180.

Sahin, B., Senol, Y.E., 2015. A novel process model for marine accident analysis by using generic fuzzy-AHP algorithm. J. Navig. 68 (1), 162-183.

Santos, M., Silva, J., Moura-Pires, J., Wachowicz, M., 2012. Automated traffic route identification through the shared nearest neighbour algorithm. In: Gensel, J. Josselin, D., Vandenbroucke, D. (Eds.), Bridging the Geographic Information Sciences. Springer, Berlin Heidelberg, pp. 231-248. http://dx.doi.org/ 10.1007/978-3-642-29063-3_13.

Schwehr, K., 2011. Vessel Tracking Using the Automatic Identification System (AIS) During Emergency Response: Lessons from the Deepwater Horizon Incident. US Hydro, Tampa, FL, pp. 1-22〈http://tinyurl.com/AIS-ushydro〉.

Seaman, D.E., Powell, R.A., 1990. Identifying patterns and intensity of home range use. In: International Conference on Bear Research and Management, pp. 243-249.

Seaman, D.E., Powell, R.A., 1996. An evaluation of the accuracy of kernel density estimators for home range analysis. Ecology 77 (7), 2075-2085.

Sormunen, O.-V.E., Goerlandt, F., Häkkinen, J., Posti, A., Hänninen, M., Montewka, J., Ståhlberg, K., Kujala, P., 2014. Uncertainty in maritime risk analysis: extended case study on chemical tanker collisions. Proc. Inst. Mech. Eng. Part M J. Eng. Marit. Environ. 30, 2014. http://dx.doi.org/10.1177/1475090213515640, First published on January.

Squire, D., 2003. The hazards of navigating the Dover Strait (Pas-de-Calais) traffic separation scheme. J. Navig. 56 (2), 195-210.

Steiniger, S., Hunter, A.J.S., 2013. A scaled line-based kernel density estimator for the retrieval of utilization distributions and home ranges from GPS movement tracks. Ecol. Inf. $13(0), 1-8$.

Suman, S., Nagarajan, V., Sha, O.P., Khanfir, S., Kobayashi, E., Malik, A.M.b.A., 2012. Ship collision risk assessment using AIS data. Int. J. Innovative Res. Dev. 10, 509-524.

Szlapczynski, R., 2013. Evolutionary sets of safe ship trajectories within traffic separation schemes. J. Navig. 66 (1), 65-81.

Tsatcha, D., Saux, É., Claramunt, C., 2014. A bidirectional path-finding algorithm and data structure for maritime routing. Int. J. Geogr. Inf. Sci. 28 (7), 1355-1377.

Tzavella, K., Ulmke, M., 2014. Semi-automatic sea lane extraction combining particle filtering (PF) and GIS. In: Vogler, R., Car, A., Strobl, J., Griesebner, G. (Eds.), Geoinformatics Forum (GI-Forum). Geospatial Innovation for Society, Salzburg, pp. 2-11. http://dx.doi.org/10.1553/giscience2014s2.

UKHO, 2012. List of traffic separation schemes shown on Admiralty Charts. 〈http:// tinyurl.com/TSS-UKHO>.

Vander Wal, E., Rodgers, A.R., 2012. An individual-based quantitative approach for delineating core areas of animal space use. Ecol. Modell. 224 (1), 48-53.

Wang, N., 2013. A novel analytical framework for dynamic quaternion ship domains. J. Navig. 66 (2), 265-281.

Winkle, W.V., 1975. Comparison of several probabilistic home-range models. J. Wildl. Manage. 39 (1), 118-123.

Zaman, M.B., Kobayashi, E., Wakabayashi, N., Khanfir, S., Pitana, T., Maimun, A., 2014. Fuzzy FMEA model for risk evaluation of ship collisions in the Malacca Strait: based on AIS data. J. Simul. 8 (1), 91-104.

Zhang, J., Yan, X., Chen, X., Sang, L., Zhang, D., 2012. Proc. Inst. Mech. Eng. Part M J. Eng. Marit. Environ. A novel approach for assistance with anti-collision decision making based on the International Regulations for Preventing Collisions at Sea 226 (3), 250-259. http://dx.doi.org/10.1177/1475090211434869.

Zhang, J., Hull, V., Ouyang, Z., 2013. A review of home range studies. Acta Ecol. Sin. 33 (11), 3269-3279. http://dx.doi.org/10.5846/stxb201201050017. 